\title{
Germanica
}

\section{La « Nouvelle Objectivité » - label ou sensibilité ?}

Pierre Vaydat

\section{(2) OpenEdition}

Journals

\section{Édition électronique}

URL : http://journals.openedition.org/germanica/2378

DOI : 10.4000/germanica.2378

ISSN : 2107-0784

Éditeur

Université de Lille

\section{Édition imprimée}

Date de publication : 31 décembre 1991

Pagination : 9

ISSN : 0984-2632

\section{Référence électronique}

Pierre Vaydat, «La « Nouvelle Objectivité » - label ou sensibilité ? », Germanica [En ligne], 9 | 1991, mis en ligne le 07 juillet 2014, consulté le 06 octobre 2020. URL : http://journals.openedition.org/ germanica/2378; DOI : https://doi.org/10.4000/germanica.2378

Ce document a été généré automatiquement le 6 octobre 2020.

(c) Tous droits réservés 


\title{
La « Nouvelle Objectivité » - label ou sensibilité?
}

\author{
Pierre Vaydat
}

On a souvent accusé la Neue Sachlichkeit d'être insaisissable, une appellation arbitraire appliquée à des phénomènes culturels hétérogènes, rapprochés artificiellement parce qu'ils sont contemporains. Les études que réunit ce numéro montreront qu'il n'en est rien : il s'agit au départ d'une forme de relation intellectuelle et esthétique gratifiante avec un monde en rapide mutation. La tendance est à l'établissement d'un esprit délibérément anti-pathétique, d'un anti-romantisme qui n'exclut pas la pose. Les paradoxes de la Neue Sachlichkeit sont bien connus : elle unit l'affectation de froideur à la volonté militante, épouse la stabilisation tout en récupérant l'avant-garde, commence par la résignation à la triste vérité après qu'ont été déçus les espoirs de l'expressionnisme pour se transformer en adhésion à la modernité industrielle et à la société de masses, finissant, après 1930, par produire une série de constats fixant avec une exactitude et un relief extraordinaires le processus de désagrégation de la République de Weimar. La Neue Sachlichkeit n'est pas seulement un principe de ralliement esthétique (avec parfois des allures de label accrocheur). Durant les années de la stabilisation, elle a voulu être aussi un principe régulateur de la vie sociale, favoriser la démocratie industrielle en suscitant de nouvelles habitudes mentales. 